\title{
Impact of Paracetamol Impurities on Face Properties: Investigating the Surface of Single Crystals Using TOF-SIMS
}

Sara Ottoboni, ${ }^{* \dagger, \perp}{ }^{\dagger}$ Michael Chrubasik, ${ }^{\dagger}, \|, \perp$ Layla Mir Bruce, ${ }^{\ddagger}, \perp$ Thai Thu Hien Nguyen, ${ }^{\dagger, \perp}$

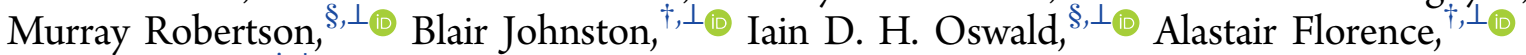
and Chris Price ${ }^{\dagger, \perp}$

${ }^{\dagger}$ EPSRC Centre for Innovative Manufacturing in Continuous Manufacturing and Crystallisation, University of Strathclyde, Technology and Innovation Centre, Level 6, CMAC, 99 George Street, G1 1RD Glasgow, U.K.

${ }^{\ddagger}$ Department of Chemical \& Process Engineering, University of Strathclyde, Level 4, James Weir Building, 75 Montrose Street, G1 1XQ Glasgow, U.K.

${ }^{\S}$ Strathclyde Institute of Pharmacy \& Biomedical Sciences (SIPBS), University of Strathclyde, 161 Cathedral Street, G4 0RE, Glasgow, U.K.

"National Physical Laboratory Scottish Hub, University of Strathclyde, G1 1RD Glasgow, U.K.

Supporting Information
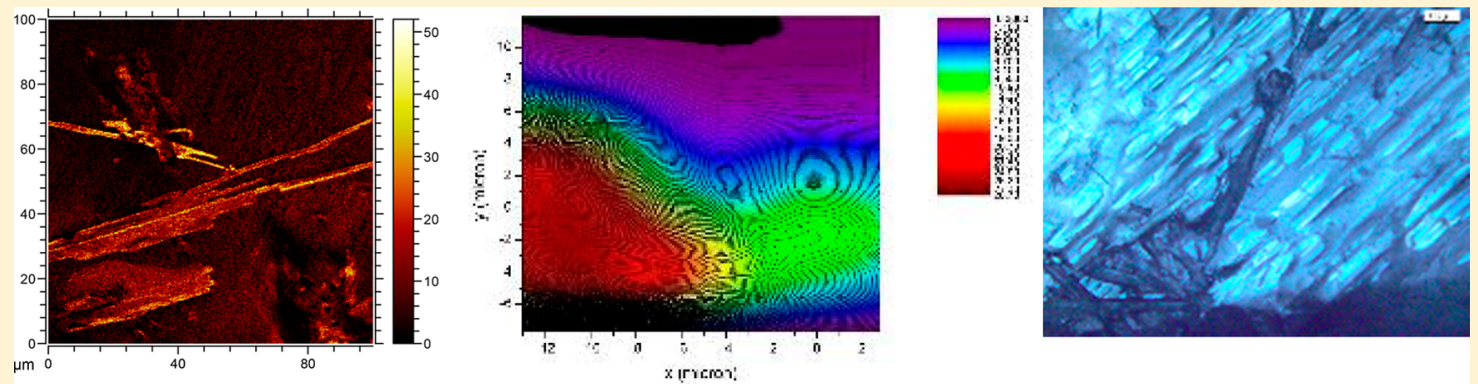

ABSTRACT: Understanding the mechanism of interaction between pharmaceutical molecules (APIs) and impurities on crystal surfaces is a key concept in understanding purification and for the design of pharmaceutical crystallization processes. Several techniques may be used to study crystal surface properties, such as scanning electron microscopy (SEM) and X-ray photoelectron spectroscopy (XPS), which provide detailed imaging and elemental surface characterization. Time of flight secondary ion mass spectrometry (TOF-SIMS) is valuable in determining molecular identity and distribution. By combining TOF-SIMS, SEM, and optical (OM) and Raman microscopies, we can evaluate the usefulness of TOF-SIMS as a surface characterization technique for pharmaceutical crystals. 4-Nitrophenol has been selected as an impurity that can be incorporated during crystallization of acetaminophen (paracetamol). This study explores the distribution of impurity and its concentration on the different crystal faces of samples obtained by crystallization over a range of impurity loadings and supersaturation conditions. Raman maps of paracetamol single crystal faces were analyzed using the characteristic Raman peak intensity of 4-nitrophenol to identify regions where it accumulated; Raman maps of three single crystals produced in the presence of 4-nitrophenol using different crystallization procedures highlight how it can be difficult to detect very low concentrations of similar chemical species. In contrast, the 4-nitrophenol monoisotopic mass obtained via TOF-SIMS was shown to be detectable in all the three single crystals produced. This indicates that TOF-SIMS can be a valuable technique for single crystal impurity distribution mapping even when the impurity concentration is very low.

\section{INTRODUCTION}

Active pharmaceutical ingredients (API) are typically produced by chemical synthesis. Various components, including residual solvents and trace amounts of inorganic and organic compounds including unreacted starting materials and byproducts, are typically present at the end of the synthesis and are removed to a large extent by crystallization. All of these substances that remain in the final API product are defined as impurities. Impurities related to the synthesis can be classified as intermediate, penultimate intermediate, and byproducts that are produced during the different synthesis steps, all of which have chemical structures that are, to some degree, similar to the API, as are any degradation products. ${ }^{1}$

Structurally related substances can change API crystallization behavior. When the solubility of these substances is similar to or less than the API solubility, elimination of these substances

Received: October 5, 2017

Revised: February 14, 2018

Published: March 26, 2018 
Table 1. Crystallization Procedure for Single Crystals Prepared in This Work

\begin{tabular}{|c|c|c|}
\hline crystallization method & preparation & single crystals obtained \\
\hline cooling crystallizations & $\begin{array}{l}\text { raw material: supersaturated solution of paracetamol with } 4 \text { mol \% of } 4 \text { - } \\
\text { nitrophenol } \\
\text { temperature profile: dissolution }=50{ }^{\circ} \mathrm{C} \\
\text { cooling }=50{ }^{\circ} \mathrm{C} \text { down to } 5{ }^{\circ} \mathrm{C} \\
\text { isolation }=5{ }^{\circ} \mathrm{C}\end{array}$ & $\begin{array}{l}\text { pure paracetamol }(\mathrm{PP}) \\
\text { pure 4-nitrophenol (PN) } \\
\text { paracetamol crystal with the presence of } 4 \mathrm{~mol} \% 4 \text { - } \\
\text { nitrophenol (P4\%N) }\end{array}$ \\
\hline $\begin{array}{l}\text { crystal with drop of } 4- \\
\text { nitrophenol }\end{array}$ & $\begin{array}{l}\text { raw material: paracetamol single crystal grown by the method above, 4- } \\
\text { nitrophenol solution ( } 1500 \mathrm{mg} / \mathrm{g} \text { ethanol) } \\
\text { procedure: dropping 4-nitrophenol solution on a flat dominant surface of } \\
\mathrm{PP} \text { and allowing the solvent to evaporate }\end{array}$ & $\begin{array}{l}\text { layer of 4-nitrophenol crystals deposited on the surface of } \\
\text { the paracetamol crystal surface (PDN) }\end{array}$ \\
\hline $\begin{array}{l}\text { crystal with } 4- \\
\text { nitrophenol deposit } \\
\text { grown epitaxially }\end{array}$ & $\begin{array}{l}\text { raw material: paracetamol single crystal grown by the method above, } \\
\text { saturated solution of 4-nitrophenol in hexane } \\
\text { temperature profile: immersion = room temperature } \\
\text { cooling = room temperature down to } 5{ }^{\circ} \mathrm{C} \\
\text { isolation = room temperature } \\
\text { procedure: immersing the PP crystal in the saturated solution of } 4- \\
\text { nitrophenol and allowing } 4 \text {-nitrophenol crystals to grow on the } \\
\text { paracetamol crystal surface }\end{array}$ & $\begin{array}{l}\text { very fine needle-like 4-nitrophenol crystals were crystallized } \\
\text { on the surface of paracetamol crystal and in the solution } \\
\text { (PEN) }\end{array}$ \\
\hline
\end{tabular}

may be difficult. Furthermore, these impurity molecules have the capability to modify API solubility, nucleation, and crystal growth resulting in changes in crystal morphology and crystallization kinetics.

Paracetamol, also known as acetaminophen, is a molecular organic compound and an API that shows analgesic and antipyretic effects. ${ }^{2}$ Paracetamol consists of a benzene ring core, substituted by one hydroxyl group and a methylamide group in the para position. ${ }^{3,4}$ The amide and hydroxyl groups act as hydrogen bond donors, whereas the carbonyl and hydroxyl groups act as acceptors. Paracetamol has three different polymorphic forms: form I, the stable form, crystallizes in a monoclinic structure; metastable form II adopts an orthorhombic structure; and form III is the most metastable form. ${ }^{5-8}$ The habit of paracetamol form I crystals can vary from being plate-like to needle-like depending on the crystallization conditions. The calculated principal facets of paracetamol (BFDH modeling) and paracetamol functional groups exposed on each facet are evaluated in the Supporting Information.,10

Hendriksen and Grant ${ }^{11}$ showed that some substances, which are structurally related to paracetamol, such as acetanilide and metacetamol inhibit the primary nucleation of paracetamol in aqueous solution. They also suggested that the nucleation rate is modified through a mechanism similar to that previously reported for crystal growth modification by structurally related additives. Hendriksen et al. ${ }^{10}$ and then Kuvadia and Doherty ${ }^{12}$ have proposed that structurally related additives may influence the nucleation and growth of crystals in three principal ways:

- Blocking adsorption of solute molecules onto the crystal surface and therefore inducing morphological changes; $^{10,13}$ for example, 4-acetoxyacetanilide acts as a blocking impurity inhibiting crystal growth on the (110) facet.

- Docking onto the surface and become incorporated into the crystal lattice without significantly affecting the arrival of further API molecules; ${ }^{10}$ metacetamol operates in this way.

- Disrupting the emerging nucleus to inhibit the nucleation process; ${ }^{10}$ metacetamol is also described as a disrupting impurity.

Various experimental methodologies to evaluate the role of structurally related impurities on crystal surface texture and crystal morphology are reported in the literature. ${ }^{10,13-17}$ Optical (OM) and scanning electron microscopy (SEM) are useful to investigate crystal morphology, aspect ratio, and, to provide some information about surface texture. Saleemi ${ }^{17}$ reported the influence of metacetamol on paracetamol crystal morphology, whereby the habit was altered from a tabular to columnar with increasing metacetamol content during crystallization. The authors also analyzed the variation of induction time, crystal size distribution (PSD), and solution concentration during paracetamol crystallization; these were enabled by the use of in situ UV spectroscopy and focused beam reflectance measurements (FBRM)

Prasad et al. ${ }^{16}$ and Chow et al. ${ }^{15}$ examined the role of 4 acetoxyacetanilide solution concentrations and supersaturation levels on the transition of paracetamol crystals from columnar to plate-like habits. In addition to this they were able, using scanning and optical microscopy, to investigate shape and strain/defect content, as well as quantification of 4acetoxyacetanilide incorporation into paracetamol crystals.

Optical and electron microscopy and atomic force microscopy (AFM) allow surface roughness and crystal growth mechanism to be explored. For example, Thompson et al. ${ }^{13}$ investigated how the morphology and chemical properties of the (001) face of paracetamol can be affected by the presence of different structurally related impurities.

One of the challenges faced in previous investigations was extracting information about both the chemical and topographic character of individual crystal faces using a single technique. In this work, we have explored alternative analytical tools such as Raman mapping and time of flight secondary ion mass spectrometry (TOF-SIMS) in order to evaluate their effectiveness and sensitivity when used to simultaneously detect impurity distribution on the crystal surface and surface modification caused by the structurally related impurities.

TOF-SIMS is a surface-sensitive analytical technique that is extensively used in material science ${ }^{18-22}$ and has begun to be applied in pharmaceutical applications in recent years. ${ }^{23-28}$ The technique utilizes a pulsed ion beam to release molecules from the outermost layers of a sample surface resulting in the emission of both neutral and charged species (atoms and molecules); the charged species are termed secondary ions. ${ }^{29,30}$ These ions, in turn, are extracted into a time-of-flight mass analyzer for detection and quantification. Moving the ion beam 
across the sample surface enables elemental and molecular surveying of the sample surface.

This study focuses on the API paracetamol and 4nitrophenol as a paracetamol related impurity. 4-Nitrophenol was chosen as the representative impurity as it is a precursor in the synthesis of paracetamol and hence could be present as an impurity during the crystallization process. We investigate the limit of detection for this impurity on crystal surfaces by preparing samples using three different crystallization techniques: cooling crystallization; surface deposition via solvent drop evaporation; and epitaxial growth. The solubility of both compounds in the different solvents (ethanol and hexane) was investigated to control the supersaturation through prediction methods using COSMOTherm and by experimental measurement by isothermal equilibration.

Optical microscopy (OM) and scanning electron microscopy (SEM) were used in combination to evaluate crystal morphology, surface character, and aspect ratio. AFM was used to study crystal surface topography; the solid state and chemical composition were determined by single crystal X-ray diffraction (SC-XRD) and HPLC, respectively.

\section{EXPERIMENTAL SECTION}

Materials. Paracetamol (4-actamidophenol, Bioxtra, $\geq 99 \%)$, 4nitrophenol ( $\geq 99 \%$ ), absolute ethanol (GC grade $\geq 99.8 \%$ ), and $n$ hexane ( $\geq 95 \%$ ) were all purchased by Sigma-Aldrich. 4-Nitrophenol is an intermediate in the synthesis of paracetamol; ${ }^{2}$ if present at the end of the synthesis, it could affect the crystallization process, and if not rejected during the crystallization, it could be incorporated into the crystal lattice. 4-Nitrophenol shows oral, respiratory, and skin toxicity. 4-Nitrophenol shows specific target organ toxicity for repeated exposure. $n$-Hexane and ethanol are flammable solvents. $n$-Hexane shows oral, respiratory, and skin toxicity. $n$-Hexane is suspect of carcinogenic effects.

Methods. To test the sensitivity limit for impurity detection on crystal faces, three different crystallization methods were implemented (Table 1).

Cooling Crystallization from Impure Solution. A single crystal of paracetamol containing 4-nitrophenol as an impurity was obtained by preparing a supersaturated solution of paracetamol $(0.88 \mathrm{~g})$ in absolute ethanol $(5 \mathrm{~g})$ by the addition of $4 \% \mathrm{~mol}$ of 4-nitrophenol $(0.029 \mathrm{~g})$. The solution was heated to $50{ }^{\circ} \mathrm{C}$ and allowed to cool to room temperature and then further to $5{ }^{\circ} \mathrm{C}$ in a refrigerator. A suitable single crystal of paracetamol with 4-nitrophenol $(\mathrm{P} 4 \% \mathrm{~N})$ of size exceeding $1 \mathrm{~mm}$ was then isolated from the solution.

Paracetamol Crystal with 4-Nitrophenol Deposited by Evaporation. Paracetamol single crystals with a surface deposit of 4-nitrophenol (PDN) were prepared by growing pure paracetamol single crystals (PP) using the same cooling crystallization procedure outlined above but in the absence of the impurity. After the pure crystals were isolated and dried at room temperature, a room temperature saturated solution of 4-nitrophenol in ethanol was prepared $(1500 \mathrm{mg} / \mathrm{g}$ ethanol). A drop of this solution was dispensed onto the dominant face of the PP crystal using a microsyringe. The solvent was allowed to evaporate at ambient temperature producing a layer of 4-nitrophenol crystals on the paracetamol crystal surface.

Crystal with 4-Nitrophenol Epitaxially Deposited. Epitaxial deposition of 4-nitrophenol (PEN) onto the surface of a paracetamol crystal was achieved by growing a pure paracetamol single crystal (PP) using the procedure described earlier followed by immersion in a saturated solution of 4-nitrophenol in hexane at room temperature (the composition was in accordance with solubility data reported in the Supporting Information). The crystal and solution was then cooled to $5{ }^{\circ} \mathrm{C}$. Hexane was selected as solvent for the 4-nitrophenol solution due to the relatively high solubility of paracetamol in ethanol, which may have caused slight dissolution of the single crystal during the preparation of the earlier sample. Given the much larger quantity of solvent to be used in this preparation, it was considered prudent to use an alternative solvent. Very fine needle-like 4-nitrophenol crystals were formed on the surface of paracetamol crystal and in the surrounding solution.

To provide a comparator to allow chemical and physical changes to be identified, pure crystals of paracetamol and 4-nitrophenol were prepared from an ethanol solution using the method described earlier.

Solubility Experiments. The solubility of paracetamol in ethanol was taken from the literature; ${ }^{31}$ its solubility and that of 4-nitrophenol in ethanol and hexane were compared with predictions made using COSMOTherm and with experimental measurements made by isothermal equilibration. Preweighed suspensions of paracetamol and 4-nitrophenol in ethanol and hexane were prepared and placed in an incubator (Incubator S160D, Stuart) on a multiposition stirrer plate and held isothermally at the selected equilibration temperatures of 25 , 40 , and $55{ }^{\circ} \mathrm{C}$, and equilibrated with agitation for $24 \mathrm{~h}$. Once the $24 \mathrm{~h}$ equilibration period was competed, $1 \mathrm{~mL}$ samples were taken and the mass recorded. The samples were then left without lids in a fume hood for $24 \mathrm{~h}$ to allow the solvent to evaporate. After $24 \mathrm{~h}$, the sample vials were weighed and their mass recorded. Finally, the sample vials were placed in a vacuum oven (Gallenamp) for $24 \mathrm{~h}$ at room temperature and (20 mbar) prior to recording the final dry residue mass, which was used to calculate the solubility of each compound.

Solid State and Composition Analysis. The chemical composition of single crystal samples of paracetamol with nitrophenol were analyzed using an Agilent 1290 UPLC, 6530 Q-TOF using an internal standard method. An Agilent Poroshell 120 EC-C18 $(3.0 \times 50$ $\mathrm{mm}, 2.7 \mu \mathrm{m})$ column was used. The analysis was performed at $25^{\circ} \mathrm{C}$, using a $1.5 \mathrm{~mL} / \mathrm{min}$ flow rate recording the absorbance at $230 \mathrm{~nm}$. The mobile phase was 20:80 methanol/water. The samples were prepared by dissolving the selected crystals in $100 \mathrm{~mL}$ of a $5 \% \mathrm{w} / \mathrm{w}$ methanol/water solution. A calibration curve for the 4-nitrophenol impurity was prepared using $5 \mu \mathrm{L}$ solutions containing $0.14 \mathrm{mg} / \mathrm{mL}$ paracetamol spiked with $5-15 \%(\mathrm{w} / \mathrm{w})$ of 4-nitrophenol. Samples were analyzed in triplicate. Chemical composition analysis is a destructive analysis that was performed as last analytical technique.

X-ray diffraction intensities were collected on a Bruker APEX 2 diffractometer coupled with an Incoatec IuS Mo microsource (0.71073 $\AA)$ operating at room temperature $(293 \mathrm{~K})$. A total of 780 frames was collected using three angular settings with a scan width of $0.5^{\circ}$ in omega. Two crystals from each crystallization experiment were faceindexed to assign the Miller indices.

Chemical Character and Surface Texture Evaluation. A stereomicroscope (Brunel Microscopes Ltd., BMDZ zoom stereomicroscope) was used to evaluate single crystal morphology and identify the main macroscopic features. A Leica DM6000M microscope was used in differential interference contrast (DIC) mode to analyze the surface texture of the crystals. A Hitachi TM-1000 version 02-11 scanning electron microscope was used to evaluate the microsurface texture and features of the crystals. The operating conditions for the SEM experiments were back scattered detector, accelerating voltage $15000 \mathrm{~V}$, magnification $200 \times$, working distance $6700 \mu \mathrm{m}$, emission current $57.4 \mathrm{~mA}$, scan speed slow, and vacuum conditions $15.0 \mathrm{kV}$.

Raman microscopy in mapping mode and TOF-SIMS were used to investigate the distribution of impurities on the crystal faces.

Raman microscopy may be operated in mapping mode to analyze localized regions of samples by vibrational microspectroscopy. ${ }^{32-34}$ Mapping involves the sequential measurement of the Raman spectra of adjacent regions of a sample by moving each region of the surface of the sample into the focal point of a Raman microscope. A Horiba Raman Xplora microscope was used to perform the Raman mapping. A $532 \mathrm{~nm}$ laser source coupled with a $50 \times$ objective $(1.23 \mu \mathrm{m}$ spatial beam width), $50 \mu \mathrm{m}$ of slit, and $100 \mu \mathrm{m}$ aperture was used to collect the Raman spectra over the range 50 to $3500 \mathrm{~cm}^{-1}$ at room temperature. Data acquisition time was $2 \mathrm{~s}$ with averaging over two spectra with a delay of $2 \mathrm{~s}$. A $25 \%$ filter was used to reduce the effects of interaction of the laser with the sample. The characteristic Raman peaks for paracetamol and 4-nitrophenol were evaluated from published sources ${ }^{35,36}$ coupled with our own measurements of the 

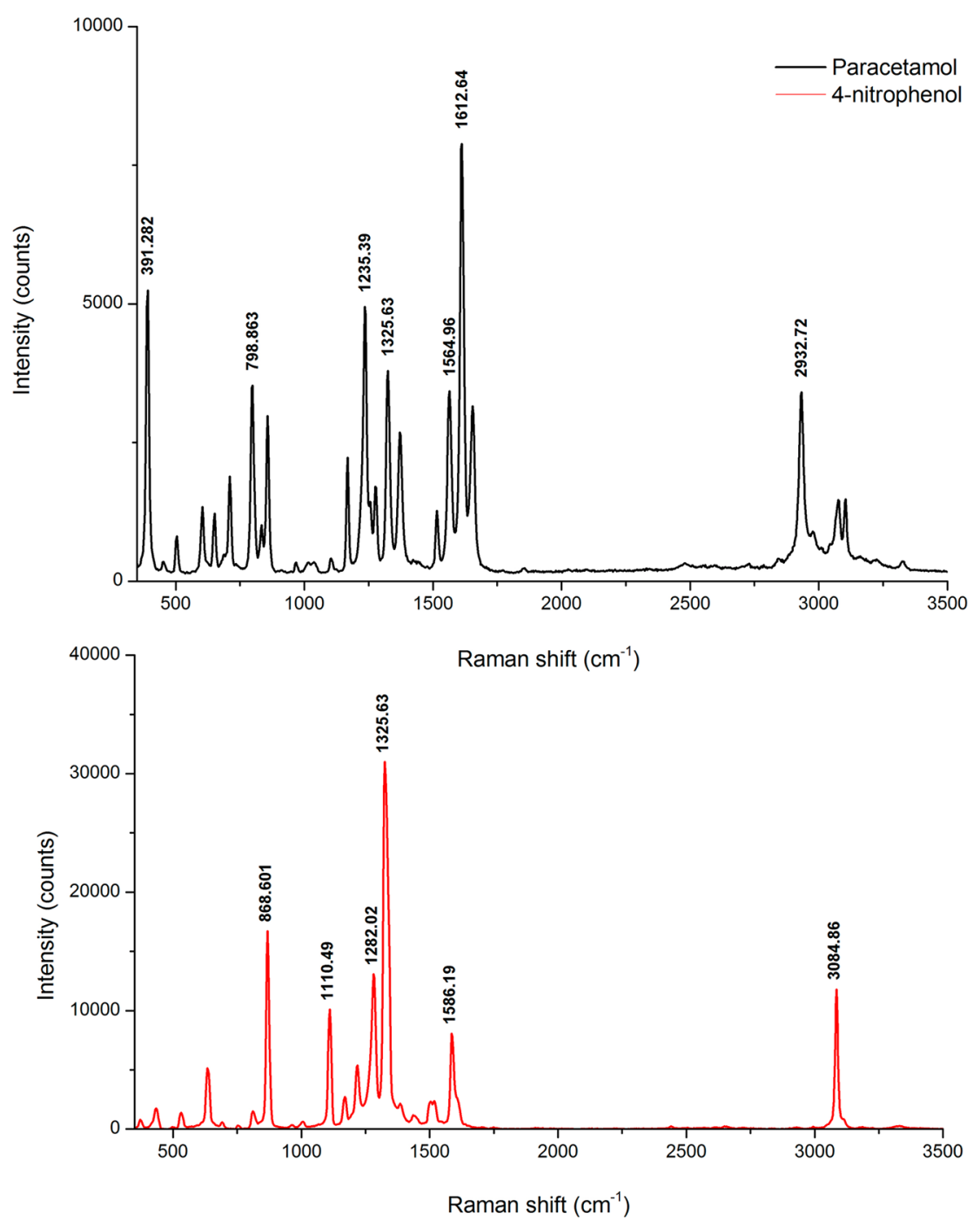

Figure 1. Raman spectra of paracetamol (PP) (top) and 4-nitrophenol (PN) (bottom).

individual Raman spectra of paracetamol (PP) and 4-nitrophenol (PN) crystals. The main 4-nitrophenol Raman peak has a characteristic frequency of $1111 \mathrm{~cm}^{-1}$, which is related to $-\mathrm{CN}$ stretching of the nitro group. ${ }^{36}$ Based on this characteristic peak, $2 \mathrm{D}$ maps were created for $20 \times 20 \mu \mathrm{m}$ or $10 \times 10 \mu \mathrm{m}$ sampling areas by calculation of the intensity ratio between peak and baseline intensity; this was performed using Origin software. Measurements were conducted on crystals obtained from the three different crystallization conditions.

The TOF-SIMS instrument used in this study was a TOF-SIMS 5 from IONTOF, which has four different operational modes; surface spectroscopy, surface imaging, depth profiling, and 3D-imaging. Depth profiling approach is a destructive analysis. Of these modes, surface spectroscopy and surface imaging were the main approaches used. Data were collected in both positive and negative polarity for all the samples that were prepared. Negative polarity was selected as the preferred mode due to enhanced molecular polarizability of the 4nitrophenol fragments. All images were collected using the $\mathrm{Bi}_{3}{ }^{+2}$ ion source with settings adjusted toward high lateral resolution $(30 \mathrm{keV}$ base setting, due to double charge effective $60 \mathrm{keV}, 100 \mathrm{~ns}$ pulse width, $0.05 \mathrm{nA}$ beam current). All crystals were analyzed, in each case, as a sample area of $100 \times 100 \mu \mathrm{m}$. While the PP and PN crystals were recorded at $256 \times 256 \mathrm{px}$ raster size, $\mathrm{P} 4 \% \mathrm{~N}$ was recorded at $1024 \times$ $1024 \mathrm{px}$ raster size. The total dose densities recorded were $4 \times 10^{11}$ ions $/ \mathrm{cm}^{2}$ for the PP and PN crystals and $9 \times 10^{11}$ ions $/ \mathrm{cm}^{2}$ for the $\mathrm{P} 4 \mathrm{~N}$ crystal. To aid the assignment of all mass fragments, the software tools NIST 08 MS Demo and AMDIS 2.6 were used.
Atomic force microscopy (AFM) was carried out using a Bruker AFM with Icon Scanner system and Scan Asyst in air experiment mode, equipped with a MPP-12120-10 tip. The dimensions of the scan area were $50 \times 50 \mu \mathrm{m}$ for each of the samples studied.

\section{RESULTS AND DISCUSSION}

Chemical Character and Surface Texture Evaluation. The SC-XRD, OM, SEM, and AFM results are reported in the Supporting Information. The SC-XRD of the pure crystals were concordant with the literature values for form I (monoclinic) of paracetamol $^{8,37,38}$ and the alpha form of 4-nitrophenol. ${ }^{3}$ The lattice parameters of $\mathrm{P} 4 \% \mathrm{~N}$ suggest that 4-nitrophenol modifies the paracetamol crystal lattice without causing a polymorphic change; however, it is known that the errors calculated from Xray data are overoptimistic given the area-detector and the systematic errors in data collection. ${ }^{39,40}$ Observation reveals a new crystal face and changes in face shapes on the paracetamol crystal grown in the presence of 4-nitrophenol compared with the crystals grown from pure solution. The change in morphology associated with the incorporation of 4-nitrophenol in the paracetamol lattice is presumed to be due to the reduced capability of the nitro group to form hydrogen bonds compared with the amide. This indicates that the 4-nitrophenol, though present in small quantities, acted as a crystal face modifier. 
OM in DIC mode, SEM images, and AFM images were examined to assess surface texture characteristics of pure paracetamol (PP), pure 4-nitrophenol (PN), and the three different impure crystals $\mathrm{P} 4 \% \mathrm{~N}, \mathrm{PDN}$, and PEN (the images are available in the Supporting Information). Comparing pure paracetamol and pure 4-nitrophenol single crystals surface texture differences and different edge shapes were observed: PP crystal shows characteristic edge steps, while rounded and shorter steps are visible on the PN crystal. Examination of the $\mathrm{OM}$ and SEM images indicates that 4-nitrophenol added as impurity during growth acted as a texture modifier, increasing the number of steps and other surface defects; this is consistent with the observation of Prasad and Thompson. ${ }^{13,16}$ PDN crystal were examined within the perimeter area of the evaporated 4-nitrophenol saturated drop. Needle-like crystals of 4-nitrophenol were randomly distributed in the core area of the drop, while at the perimeter they were aligned in the direction of spread. Areas not covered by the spreading drops of 4-nitrophenol solution showed characteristic paracetamol surface texture. The 4-nitrophenol crystals grown on the paracetamol crystal surface by rapid solvent evaporation exhibit a needle-like morphology that is quite different from the slowly grown 4-nitrophenol crystal for SCXRD. This may be due to rapid growth by evaporation or, alternatively, could be due to the formation of the beta polymorph of 4-nitrophenol, ${ }^{41}$ which have a needle-like morphology (the 4-nitrophenol crystals were too small to determine their crystal form). The epitaxially grown crystals including both micrometer and nanometer size crystals of 4-nitrophenol on the paracetamol crystal surface are seen in the OM image. These crystals showed the same needlelike shape observed when 4-nitrophenol was deposited by evaporation of a drop of ethanol saturated solution.

Raman and TOF-SIMS Analysis. Raman microscopy in mapping mode and TOF-SIMS were evaluated as complementary techniques, both have the potential to allow the distribution of 4-nitrophenol on the crystal surface to be determined. As described previously three different crystallization techniques were used to prepare samples containing both paracetamol and 4-nitrophenol with which to evaluate the sensitivity of these two analytical tools to investigate concentration and distribution. Raman spectra of the pure PP and PN crystals were collected to establish the differences in the spectra between the two compounds to identify characteristic Raman bonds so that the local composition could be mapped.

Anitha and co-workers ${ }^{42,43}$ reported the assignment of spectral bands for paracetamol, while Vijayalakshmi et al. ${ }^{36}$ reported the assignment of the Raman bands for 4-nitrophenol. Characteristic 4-nitrophenol Raman peaks were 303, 869, 1110, 1586 , and $3085 \mathrm{~cm}^{-1}$. Due to the absence of overlapping features in the spectral region, the $\mathrm{CN}$ stretching peak at 1111 $\mathrm{cm}^{-1}$ was selected for evaluating the presence of 4-nitrophenol on the paracetamol crystal surface (Figure 1). The Raman maps presented in Figures 2-4 were obtained by tracking this characteristic peak of 4-nitrophenol with respect to the difference between the maximum peak intensity and baseline intensity. By processing the spectra in this way, concentration contour maps were generated.

Regions of the crystal surfaces were selected to maximize the probability of detecting the 4-nitrophenol. In the case of the crystal grown from paracetamol solution containing $4 \mathrm{~mol} \% 4$ nitrophenol, $\mathrm{P} 4 \% \mathrm{~N}$, the Raman map was constructed across a growth step (Figure 2), while in the case of the crystal with 4-
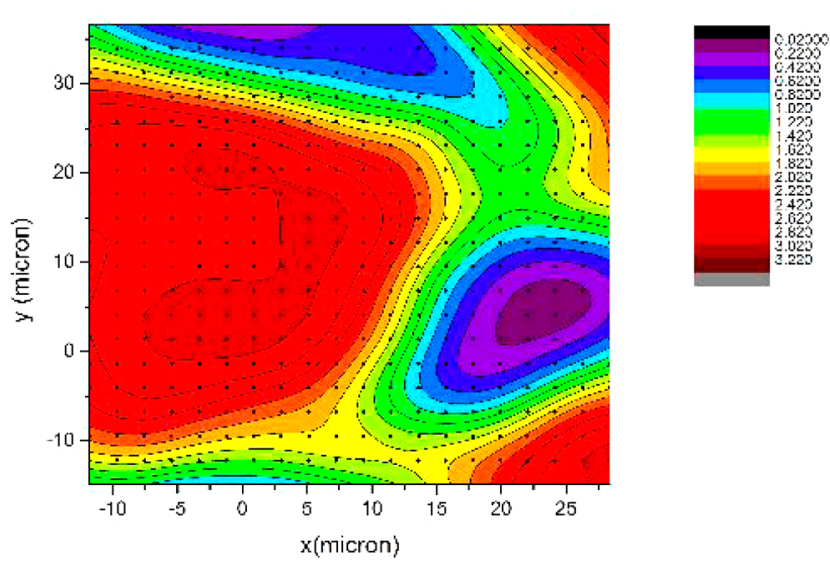

Figure 2. Raman map of $\mathrm{P} 4 \% \mathrm{~N}$ crystal. Crystal was analyzed in a step area. Area of detection $20 \times 20 \mu \mathrm{m}$. Black dots on the map correspond to the position of the laser detection. Scale is related to the intensity of the 4-nitrophenol peak with respect to the baseline.

nitrophenol solution deposited by evaporation, PDN, the detection area was localized on the perimeter area of the drop (Figure 3). In the case of the epitaxially deposited 4-

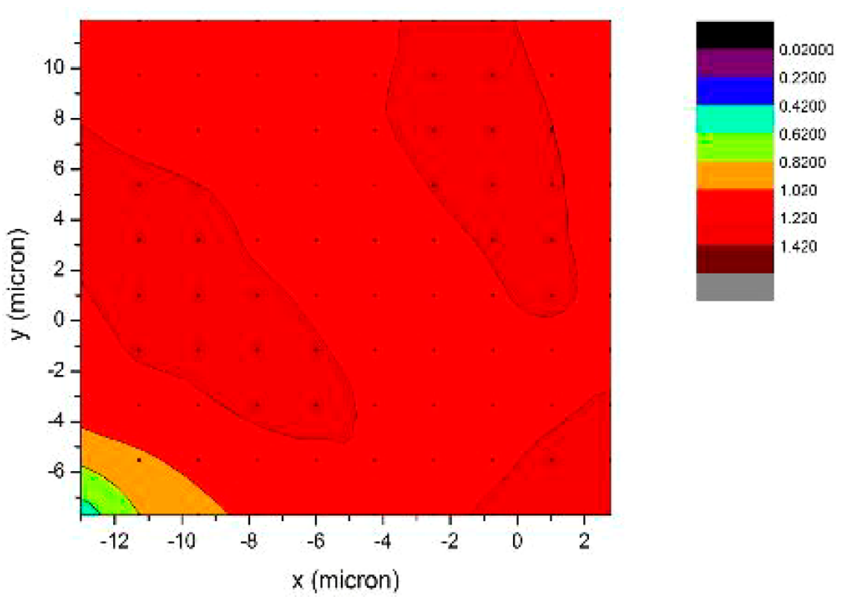

Figure 3. Raman map of PDN crystal. The surface feature of the crystal analyzed in the perimeter area where a drop of 4-nitrophenol solution had evaporated. Area of detection $10 \times 10 \mu \mathrm{m}$. The black dots on the map correspond to the position of the laser detection. Scale is related to the intensity of the 4-nitrophenol peak with respect to the baseline.

nitrophenol, PEN, the map centered on an area rich in needle-like 4-nitrophenol crystals (Figure 4). Comparing Raman maps of P4\%N, PDN, and PEN crystals, only the PEN crystal showed a significant difference between peak and baseline intensity, and in some areas, the peak intensity to baseline intensity ratio at the selected characteristic wavelength exceeded 10. This indicates that, under favorable conditions, Raman microscopy may be used in mapping mode to evaluate the distribution of chemical species.

The TOF-SIMS mass spectra and maps of the three different crystals were obtained in a similar way to the Raman maps. The pure PP and PN crystals were analyzed to obtain mass spectra of these two pure crystals in order to identify the characteristic mass fragments ion.

To verify the mass spectra obtained and to confirm the fragmentation ion identities, two software tools were used; 


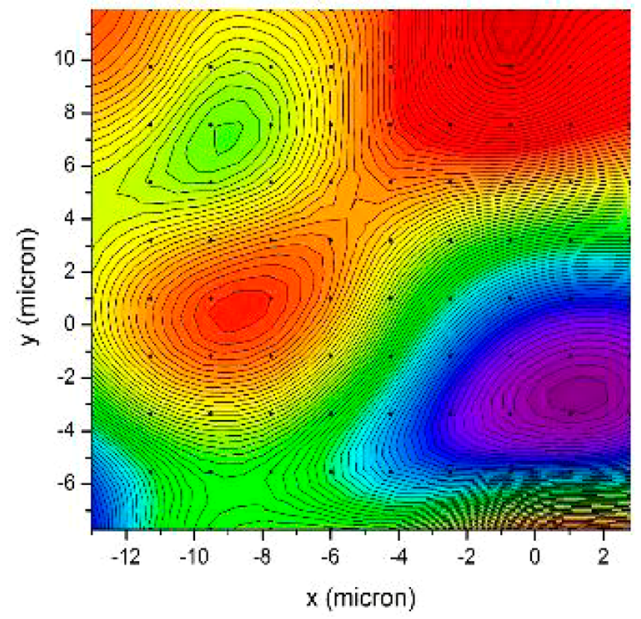

Figure 4. Raman map of PEN crystal. The area of the crystal analyzed was in an area where 4-nitrophenol needle-like crystals were concentrated. Area of detection $10 \times 10 \mu \mathrm{m}$. The black dots on the map correspond to the centers of the spectrum collections. Scale is related to the intensity of the 4-nitrophenol peak with respect to the baseline.

NIST 08 MS Demo and AMDIS 2.6 from NIST. The 10 largest molecular fragment peaks from paracetamol and 4-nitrophenol are listed and their mass ion identified in the Supporting Information.

The distinctive molecular fragments for 4-nitrophenol were $38,63,65$, and $139 \mathrm{~m} / z$. Analyzing fragment mass images at $139 \mathrm{~m} / z$, which corresponds to the 4-nitrophenol monoisotopic mass, allowed the distribution of 4-nitrophenol to be determined.

TOF-SIMS mass fragment images for the $\mathrm{P} 4 \% \mathrm{~N}$ crystal suggest a homogeneous distribution of 4-nitrophenol $(138 \mathrm{~m} /$ $z$ ) across the crystal surface. The step surface texture of the crystal can be seen in Figure 5, which is consistent with SEM and OM images also obtained (see Supporting Information).

TOF-SIMS mass fragment images of the PDN crystal (Figure 6) allow the evaporated 4-nitrophenol solution drop on top of the paracetamol crystal to be investigated. The images show a layer of 4-nitrophenol $(138 \mathrm{~m} / z)$ covering a large area of the crystal with only small areas of paracetamol $(150 \mathrm{~m} / z)$ still remaining exposed.

From these images, it appears that the 4-nitrophenol drop spread across the surface leaving a covering layer of 4- nitrophenol behind, the image does not, however, reveal the shape of the individual impurity crystals.

Figure 7 shows the TOF-SIMS mass ion fragment images of the PEN crystal. A needle-shaped 4-nitrophenol crystal is clearly seen at $138 \mathrm{~m} / z$. The corresponding image for the molecular ion fragment of paracetamol $(150 \mathrm{~m} / z)$ shows the uniform spread of paracetamol; the area covered by the 4nitrophenol appears darker as the surface of the paracetamol crystal is not accessed by the ionization beam. This sequence of figures (Figures 5-7) demonstrates the capability of TOFSIMS to evaluate the distribution of different chemical species on crystal surfaces.

\section{CONCLUSIONS}

Three different approaches, epitaxy, droplet evaporation, and cooling crystallization were used to create paracetamol crystals with molecules of 4-nitrophenol present on the crystal surface in order to study effectiveness of different analytical techniques to investigate the quantity and spatial distribution of the impurity on crystal surface and to identify any associated morphological and surface texture changes.

TOF-SIMS is a relatively new technique for pharmaceutical material characterization and allows the presence of 4nitrophenol to be verified by the distribution of the secondary-ion fragments.

The presence and spatial distribution of 4-nitrophenol crystals generated epitaxially are observed.

In the future, TOF-SIMS can be used to build 3D images showing the spatial distribution of specific molecular species deposited during crystal growth.

SEM, AFM, Raman microscopy, and TOF-SIMS were evaluated to assess the level at which the impurity 4nitrophenol can be detected.

Raman microscopy mapping reveals the impurity location when the main peak intensity ratio is more intense than the baseline; for example, the intensity difference in Figure 4 is substantially greater than in Figures 2 and 3.

OM, SEM, and AFM show crystal epitaxial growth on pure paracetamol crystal surface. They reveal surface texture changes and allow the distribution of small crystal agglomerates to be observed. These techniques can be used as complementary analytical tools to address changes in surface texture due to the presence of impurity in the crystal lattice and on the crystal surface.

This work demonstrates that TOF-SIMS analysis allowed investigation of both chemical and topographic character of
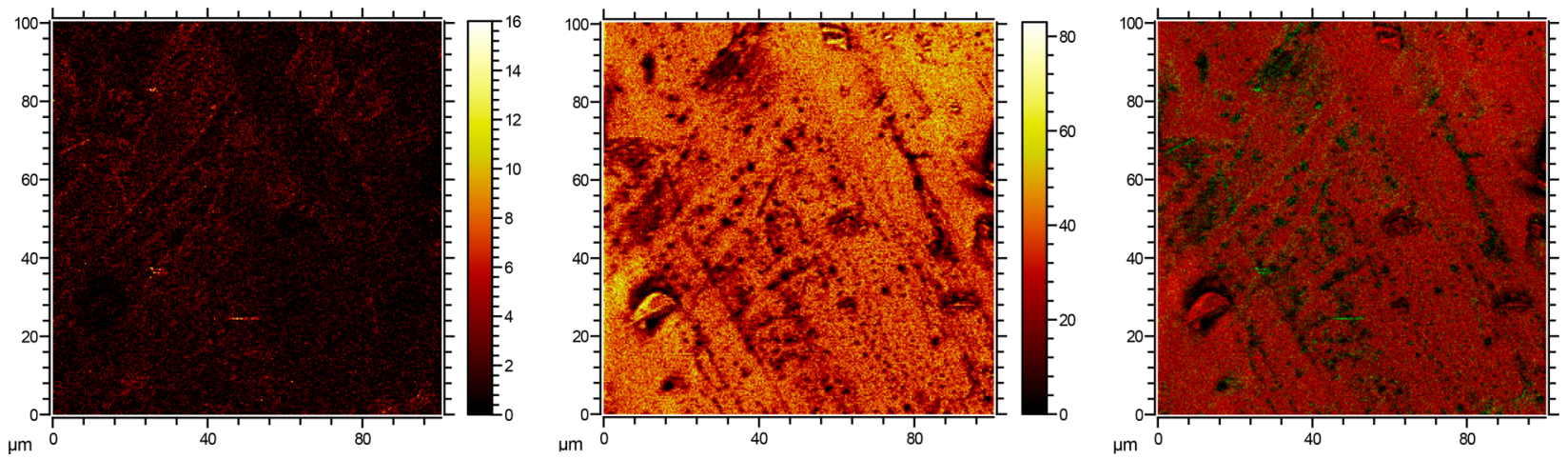

Figure 5. Paracetamol with $4 \%(\mathrm{~mol} / \mathrm{mol})$ of 4-nitrophenol. From left to right, 4-nitrophenol molecular ion image at $138 \mathrm{~m} / z(\mathrm{maximum}$ counts $=$ 16), paracetamol molecular ion image at $150 \mathrm{~m} / z$ (maximum counts $=83$ ), and RGB overlay of paracetamol (red) with 4-nitrophenol (green). 

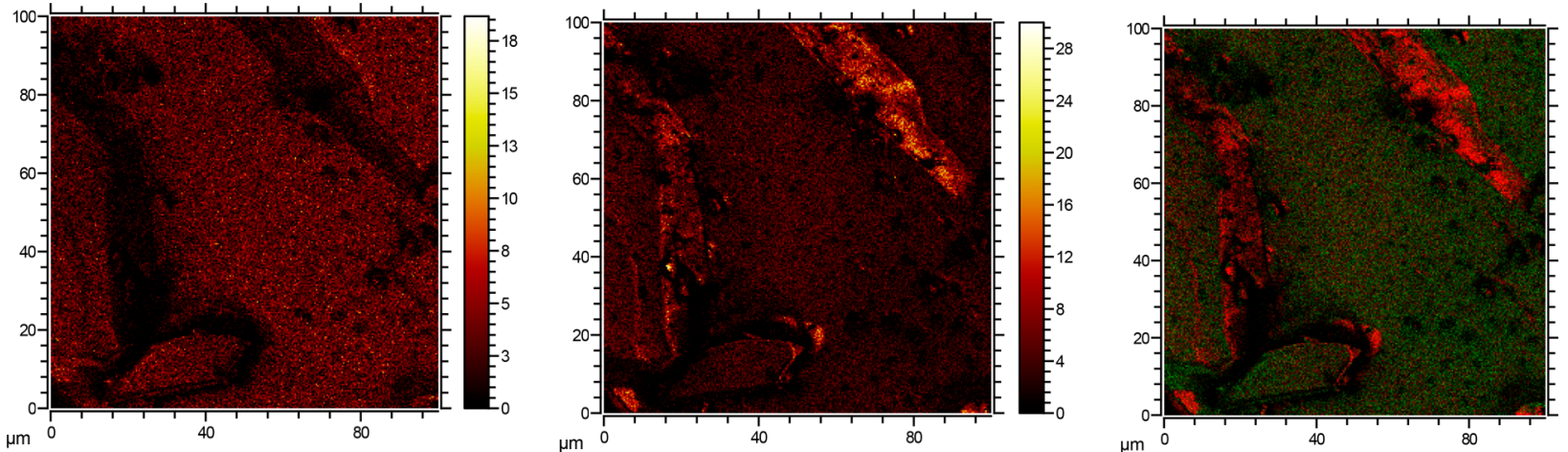

Figure 6. Paracetamol crystal with drop of 4-nitrophenol applied. From left to right, 4-nitrophenol molecular ion image at $138 \mathrm{~m} / z$ (maximum counts = 19), paracetamol molecular ion image at $150 \mathrm{~m} / z$ (maximum counts $=30)$, and RGB overlay of paracetamol (red) with 4-nitrophenol (green).
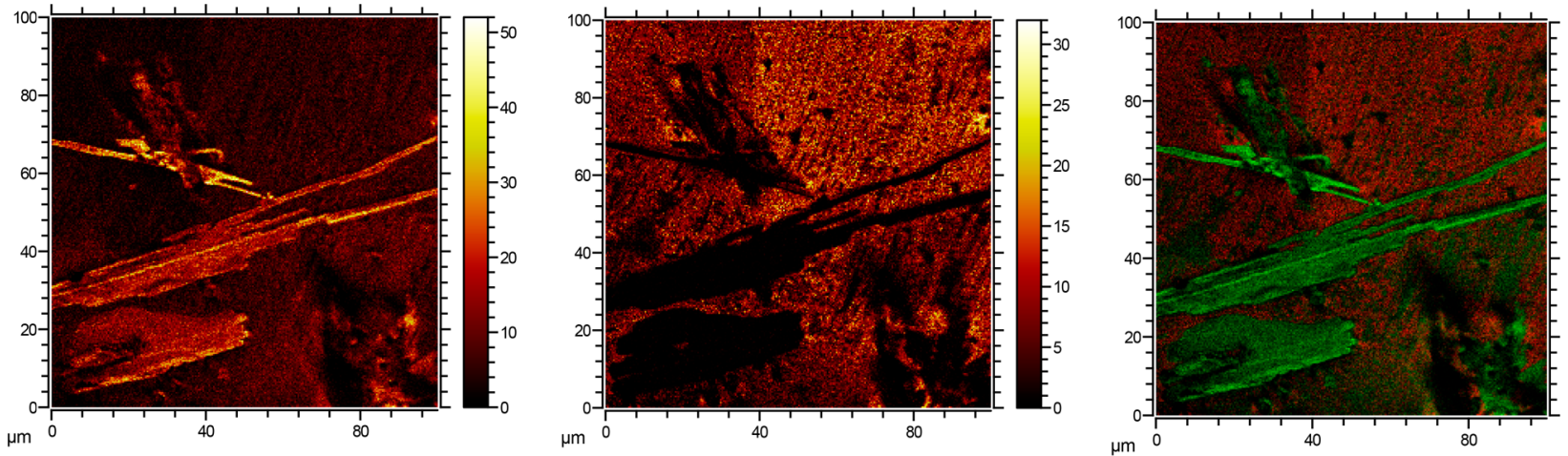

Figure 7. Suggested paracetamol with 4-nitrophenol epitaxy. From left to right, 4-nitrophenol molecular ion image at $138 \mathrm{~m} / z$ (maximum counts $=$ $52)$, paracetamol molecular ion image at $150 \mathrm{~m} / z$ (maximum counts = 32), and RGB overlay of paracetamol (red) with 4-nitrophenol (green).

crystal faces and, in combination with other complementary techniques, proves to be a valuable addition to the analysis of crystals and their impurities.

\section{ASSOCIATED CONTENT}

\section{S Supporting Information}

The Supporting Information is available free of charge on the ACS Publications website at DOI: 10.1021/acs.cgd.7b01411.

Paracetamol main face form I prediction, molecular packing diagrams based on crystallographic structure, solubility curve of paracetamol in ethanol and hexane, crystal lattice parameters of PP, PN, and P4\%N, SC-XRD images of $\mathrm{PP}$ and $\mathrm{P} 4 \% \mathrm{~N}$ crystals, stereomicroscopic images of $\mathrm{PP}, \mathrm{PN}, \mathrm{P} 4 \% \mathrm{~N}, \mathrm{PDN}$, and PEN crystals, OM images in DIC mode of PP, PN, P4\%N, PDN, and PEN, AFM maps of PP, P4\%N, PDN, and PEN, characteristic neutral fragment of paracetamol and 4-nitrophenol from NIST 08 Demo and AMDIS 2.6 (PDF)

\section{AUTHOR INFORMATION}

\section{Corresponding Author}

*Phone: 01414447109. E-mail: sara.ottoboni@strath.ac.uk.

\section{ORCID}

Sara Ottoboni: 0000-0002-2792-3011

Murray Robertson: 0000-0001-9543-7667

Blair Johnston: 0000-0001-9785-6822

Iain D. H. Oswald: 0000-0003-4339-9392

Alastair Florence: 0000-0002-9706-8364

\section{Author Contributions}

${ }^{\perp}$ All authors contributed equally.

\section{Notes}

The authors declare no competing financial interest.

\section{ACKNOWLEDGMENTS}

The authors wish to acknowledge the contributions of colleagues in each of their organizations. We are grateful to Melissa K. Passarelli, National Physical Laboratory Teddington for TOF-SIMS consultancy; Lauren O'Connor, Strathclyde Institute of Pharmacy \& Biomedical Sciences, University of Strathclyde (SIPBS), for consultancy with Raman microscopy; Bruce Wareham, SIPBS, for performing COSMOTherm calculations; Davide Erbogasto, Department of Biomedical Engineering, University of Strathclyde, for SEM analysis; Eleonora Paladino, SIPBS/CMAC for consultancy with TOFSIMS; Laura Harvey, SIPBS, for LC analysis; Monika Warzecha, SIPBS, for consultancy with AFM. The authors wish to acknowledge our funders: Chris Price, EPSRC Manufacturing Fellowship and the Centre for Innovative Manufacturing in Continuous Manufacturing and Crystallization; Sara Ottoboni and Michael Chrubasik, EPSRC Doctoral Training Centre for Innovative Manufacturing in Continuous Manufacturing and Crystallization; Michael Chrubasik, National Physical Laboratory Scottish Hub, University of Strathclyde, Glasgow, UK. The authors would like to thank the Wolfson Foundation. The authors gratefully acknowledge the financial support of the University of Strathclyde and the UK Engineering and Physical Sciences Research Council 
(EPSRC) research grants (Grant ref. EP/L014971/1 awarded to C.J.P., L.M.B., and T.T.H.N.; EP/P006965/1 awarded to B.J. and M.R.; EP/N015401/1 awarded to I.D.H.O.) and Doctoral Training Centre for Innovative Manufacturing in Continuous Manufacturing and Crystallization grant (Grant ref. EPK503289) awarded to S.O. All data underpinning this publication are openly available from the University of Strathclyde Knowledge Base at http://dx.doi.org/10.15129/ 7e48f205-e591-465c-89e2-2fc44055ala7.

\section{ABBREVIATIONS}

SIPBS, Strathclyde Institute of Pharmacy \& Biomedical Sciences; SEM, scanning electron microscopy; XPS, X-ray photoelectron spectroscopy; TOF-SIMS, time of flight secondary ion mass spectrometry; OM, optical microscopy; HPLC, high performance liquid chromatography; XRD, X-ray diffractometry; API, active pharmaceutical ingredient; EDX, energy-dispersive X-ray spectroscopy; PSD, particle size distribution; FBRM, focused beam reflectance measurement; AFM, atomic force microscopy; SC-XRD, single crystal X-ray diffractometry; $\mathrm{P} 4 \% \mathrm{~N}$, paracetamol crystal with the presence of 4 mol \% 4-nitrophenol made by cooling crystallization; PDN, paracetamol crystal with drop of 4-nitrophenol; PEN, paracetamol crystal with epitaxially grown 4-nitrophenol; PP, pure paracetamol crystal made by cooling crystallization; PN, pure 4nitrophenol made by cooling crystallization; WD, working distance; RTD, real time data

\section{REFERENCES}

(1) Prabu, S. L.; Suriyaprakash, T. N. K. Impurities and its importance in pharmacy. Int. J. Pharm. Sci. Rev. Res. 2010, 3, 66.

(2) Ellis, F. Paracetamol: A Curriculum Resource; Royal Society of Chemistry, 2002.

(3) Finnie, S.; Prasad, K. V. R.; Sheen, D. B. Sherwood, Microhardness and Dislocation Identification Studies on Paracetamol Single Crystals. J. N. Pharm. Res. 2001, 18, 674.

(4) Sudha, C.; Srinivasan, K. Understanding the effect of solvent polarity on the habit modification of monoclinic paracetamol in terms of molecular recognition at the solvent crystal/interface. Cryst. Res. Technol. 2014, 49, 865.

(5) Haisa, M.; Kashino, S.; Kawai, R.; Maeda, H. The Monoclinic Form of p-Hydroxyacetanilide. Acta Crystallogr., Sect. B: Struct. Crystallogr. Cryst. Chem. 1976, 32, 1283.

(6) Di Martino, P.; Conflant, P.; Drache, M.; Huvenne, J.-P.; GuyotHermann, A.-M. A new pure paracetamol for direct compression: The orthorhombic form. J. Therm. Anal. 1997, 48, 447.

(7) Naumov, D. Y.; Vasilchenko, M. A.; Howard, J. a. K. The Monoclinic Form of Acetaminophen at 150K. Acta Crystallogr., Sect. C: Cryst. Struct. Commun. 1998, 54, 653.

(8) Perrin, M.-A.; Neumann, M. A.; Elmaleh, H.; Zaske, L. Crystal structure determination of the elusive paracetamol Form III. Chem. Commun. 2009, 22, 3181.

(9) Shekunov, B. Y.; Aulton, M. E.; Adama-Acquah, R. W.; Grant, D. J. W. Effect of temperature on crystal growth and crystal properties of paracetamol. J. Chem. Soc., Faraday Trans. 1996, 92, 439.

(10) Hendriksen, B. A.; Grant, D. J. W.; Meenan, P.; Green, D. A. Crystallisation of paracetamol (acetaminophen) in the presence of structurally related substances. J. Cryst. Growth 1998, 183, 629.

(11) Hendriksen, B. A.; Grant, D. J. W. The effect of structurally related substances on the nucleation kinetics of paracetamol (acetaminophen). J. Cryst. Growth 1995, 156, 252.

(12) Kuvadia, Z. B.; Doherty, M. F. Effect of Structurally Similar Additives on Crystal Habit of Organic Molecular Crystals at Low Supersaturation. Cryst. Growth Des. 2013, 13, 1412.

(13) Thompson, C.; Davies, M. C.; Roberts, C. J.; Tendler, S. J. B.; Wilkinson, M. J. The effects of additives on the growth and morphology of paracetamol (acetaminophen) crystals. Int. J. Pharm. 2004, 280, 137.

(14) Shekunov, B. Y.; Grant, D. J. W.; Latham, R. J.; Sherwood, J. N. In Situ Optical Interferometric Studies of the Growth and Dissolution Behavior of Paracetamol (Acetaminophen) Crystals. 3. Influence of Growth in the Presence of p-Acetoxyacetanilide. J. Phys. Chem. B 1997, 101, 9107.

(15) Chow, A. H.-L.; Chow, P. K. K.; Zhongshan, W.; Grant, D. J. W. Modification of acetaminophen crystals: influence of growth in acqueous solutions containing p-acetoxyacetanilide on crystal properties. Int. J. Pharm. 1985, 24, 239.

(16) Prasad, K. V. R.; Ristic, R. I.; Sheen, D. B.; Sherwood, J. N. Crystallization of paracetamol from solution in the presence and absence of impurity. Int. J. Pharm. 2001, 215, 29.

(17) Saleemi, A.; Onyemelukwe, I. I.; Nagy, Z. Effects of a structurally related substance on the crystallization of paracetamol. Front. Chem. Sci. Eng. 2013, 7, 79.

(18) Winograd, N. Prospects for imaging TOF-SIMS: from fundamentals to biotechnology. Applied Surface Science, Secondary ion mass spectrometry SIMS. Appl. Surf. Sci. 2003, 203-204, 13.

(19) Verlinden, G.; Gijbels, R.; Geuens, I.; De Keyzer, R. Surface analysis of halide distributions in complex $\mathrm{AgX}$ microcrystals by imaging time-of-flight SIMS (TOF-SIMS). J. Anal. At. Spectrom. 1999, 14, 429.

(20) Rutten, F. J. M.; Roe, M. J.; Henderson, J.; Briggs, D. Surface analysis of ancient glass artefacts with ToF-SIMS: A novel tool for provenancing? Appl. Surf. Sci. 2006, 252, 7124.

(21) Park, J. S.; Kim, H. Surface characterization of plasma-modified resist patterns by ToF-SIMS analysis. Applied Surface Science, Proceedings of the Symposium on Surface Science. Appl. Surf. Sci. 2009, 256, 1604.

(22) Marques, A. F. A.; Scott, S. D.; Sodhi, R. N. S. Determining major and trace element compositions of exposed melt inclusions in minerals using ToF-SIMS. Surf. Interface Anal. 2011, 43, 436.

(23) Belu, A. M.; Davies, M. C.; Newton, J. M.; Patel, N. TOF-SIMS Characterization and Imaging of Controlled-Release Drug Delivery Systems. Anal. Chem. 2000, 72, 5625.

(24) Muster, T. H.; Prestidge, C. A. Face specific surface properties of pharmaceutical crystals. J. Pharm. Sci. 2002, 91, 1432.

(25) Prestidge, C. A.; Barnes, T. J.; Skinner, W. Time-of-flight secondary-ion mass spectrometry for the surface characterization of solid-state pharmaceuticals. J. Pharm. Pharmacol. 2007, 59, 251.

(26) Malmberg, P.; Jennische, E.; Nilsson, D.; Nygren, H. Highresolution, imaging TOF-SIMS: novel applications in medical research. Anal. Bioanal. Chem. 2011, 399, 2711.

(27) Koch, S.; Ziegler, G.; Hutter, H. ToF-SIMS measurements with topographic information in combined images. Anal. Bioanal. Chem. 2013, 405, 7161.

(28) Iuraş, A.; Scurr, D. J.; Boissier, C.; Nicholas, M. L.; Roberts, C. J.; Alexander, M. R. Imaging of Crystalline and Amorphous Surface Regions Using Time-of-Flight Secondary-Ion Mass Spectrometry (ToF-SIMS): Application to Pharmaceutical Materials. Anal. Chem. 2016, 88, 3481.

(29) Barnes, T. J.; Kempson, I. M.; Prestidge, C. A. Surface analysis for compositional, chemical and structural imaging in pharmaceutics with mass spectrometry: A ToF-SIMS perspective. Int. J. Pharm. 2011, $417,61$.

(30) Leng, Y., Ed.Materials Characterization: Introduction to Microscopic and Spectroscopic Methods, 2nd ed.; Wiley, 2013.

(31) Granberg, R. A.; Rasmuson, Å. C. Solubility of Paracetamol in Pure Solvents. J. Chem. Eng. Data 1999, 44, 1391.

(32) Morris, D. M. In Emerging Raman Applications and Techniques in Biomedical and Pharmaceutical Fields; Matousek, P., Morris, M. D., Eds.; Biological and Medical Physics, Biomedical Engineering; Springer: Berlin Heidelberg, 2010; pp 347-364.

(33) Gordon, K. C.; McGoverin, C. M. Raman mapping of pharmaceuticals. Int. J. Pharm. 2011, 417, 151. 
(34) Pyatski, Y.; Zhang, Q.; Mendelsohn, R; Flach, C. R. Effects of permeation enhancers on flufenamic acid delivery in Ex vivo human skin by confocal Raman microscopy. Int. J. Pharm. 2016, 505, 319.

(35) Al-Zoubi, N.; Koundourellis, J. E.; Malamataris, S. FT-IR and Raman spectroscopic methods for identification and quantitation of orthorhombic and monoclinic paracetamol in powder mixes. J. Pharm. Biomed. Anal. 2002, 29, 459.

(36) Vijayalakshmi, S.; Kalyanaraman, S.; Ravindran, T. R. Raman investigation with group theoretical method on structural polymorphism of the nonlinear optical hexamine: p - nitrophenol cocrystals. Phys. Scr. 2014, 89, 095501.

(37) Nichols, G.; Frampton, C. S. Physicochemical Characterization of the Orthorhombic Polymorph of Paracetamol Crystallized from Solution. J. Pharm. Sci. 1998, 87, 684.

(38) Druzhbin, D. A.; Drebushchak, T. N.; Min'kov, V. S.; Boldyreva, E. V. Crystal structure of two paracetamol polymorphs at 20K: a search for the "structure-property" relationship. J. Struct. Chem. 2015, 56, 317.

(39) Kulkarni, G. U.; Kumaradhas, P.; Rao, C. N. R. Charge Density Study of the Polymorphs of p-Nitrophenol. Chem. Mater. 1998, 10, 3498.

(40) Wójcik, G.; Mossakowska, I. Polymorphs of p-nitrophenol as studied by variable-temperature $\mathrm{X}$-ray diffraction and calorimetry: comparison with m-nitrophenol. Acta Crystallogr., Sect. B: Struct. Sci. 2006, 62, 143.

(41) Coppens, P.; Schmidt, G. M. The crystal structure of the metastable $(\beta)$ modification of p-nitrophenol. Acta Crystallogr. 1965, 18,654 .

(42) Gandhimathi, R.; Dhanasekaran, R. Third order nonlinear studies and other characterization of 4-nitrophenol (4-NP) single crystals. IOP Conf. Ser.: Mater. Sci. Eng. 2013, 43, 012004.

(43) Anitha, R.; Gunasekaran, M.; Kumar, S. S.; Athimoolam, S.; Sridhar, B. Single crystal XRD, vibrational and quantum chemical calculation of pharmaceutical drug paracetamol: A new synthesis form. Spectrochim. Acta, Part A 2015, 150, 488. 